the disease in whites than non-whites and in Jews than nonJews. ${ }^{11}$ The increased incidence of spondylitis, polyarthritis, eczema, and hay-fever in families of patients with Crohn's disease may be because some families have a genetic predisposition to a cluster of diseases. ${ }^{12}$ Abnormal immunological reactivity as possibly predisposing to Crohn's disease is being investigated. ${ }^{13}$ At present the evidence is conflicting and its significance uncertain. ${ }^{1415}$

Clinicians have an impression, if such a thing may be mentioned nowadays, that Crohn's disease is becoming more common, and epidemiological studies tend to support this view. ${ }^{1617}$ No reason for it is known. Psychological factors are generally held not to be aetiologically important. ${ }^{18}$.

Gastrointestinal complications such as obstruction, fistulae between segments of gut or gut and bladder, anal lesions, and toxic dilatation of colon are known. Hydronephrosis due to obstruction at the lower end of the ureter is seldom recognized but may be fairly common. ${ }^{19}$ The right ureter and kidney are usually affected. But the urological lesions are of much less consequence than the gastrointestinal. Carcinoma of ileum has been described in patients with Crohn's ileitis, ${ }^{20} 21$ suggesting that it is premalignant, though the incidence of this complication is very low.

Medical consequences of Crohn's disease include chronic bleeding, steatorrhoea, vitamin $\mathrm{B}_{12}$ malabsorption, proteinlosing enteropathy, and blind-loop syndromes. Recently attention has been drawn to the importance of folate deficiency. ${ }^{22}$ Bile-salt deficiency occurs because the diseased ileum cannot reabsorb these salts. ${ }^{23}$ The resulting lack of bile salts required for fat absorption by the jejunal mucosa is the likely cause of the steatorrhoea that patients with this disease sometimes experience. ${ }^{24}$

The course of Crohn's disease is so variable as to make the prognosis in an individual case exceedingly difficult. This variability also hampers trials of treatment. Careful clinical studies are therefore valuable. The one published at page 76 of the B.M.F. this week concerns pregnancy and Crohn's disease. About one-third of 77 married women of childbearing age were sterile. The remainder had 98 pregnancies

1 Crohn, B. B., Ginzburg, L., and Oppenheimer, G. D., Fournal of the American Medical Association, 1932, 99, 1323.

2 Lockhart-Mummery, H. E., and Morson, B. C., Gut, 1964, 5, 493.

2 Lockhart-Mummery, H. E., and Morson, B. C., Gut, 1964, 5, 493. 6, 515 .

- Dudeney, T. P., Proceedings of the Royal Society of Medicine, 1969, 62, 1237.

s Blackburn, G., Hadfield, G., and Hunt, A. H., St. Bartholomew's Hospital Reports, 1939, 72, 181 .

- Morson, B. C., Proceedings of the Royal Society of Medicine, 1968, 61, 79.

7 Prohaska, J., Gastroenterology, 1966, 51, 913.

8 Van Kruiningen, H. J., Gastroenterology, 1967, 53, 114.

- Kirsner, J. B., and Spencer, J. A., Annals of Internal Medicine, 1963, 59, 133.

10 Hislop, I. G., and Grant, A. K., Gut, 1969, 10, 994.

1 Monk, M., Mendeloff, A. I., Siegel, C. I., and Lilienfeld, A., Gastroenterology, 1967, 53, 198.

12 Hammer, B., Ashurst, P., and Naish, J., Gut, 1968, 9, 17.

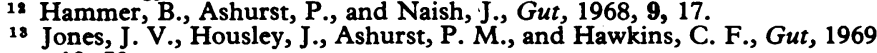
$10,52$.

14 Fletcher, J., and Hinton, J. M., Lancet, 1967, $2,753$.

15 Mitchell, D. N., Cannon, P., Dyer, N. H., Hinson, K. F. W., and Willoughby, J. M. T., Lancet, 1969, 2, 571 .

16 Evans, J. G., and Acheson, E. D., Gut, 1965, 6, 311.

17 Kyle, J., and Blair, D. W., British fournal of Surgery, 1965, 52, 215

18 Feldman, F., Cantor, D., Soll, S., and Bachrach, W., British Medical fournal, 1967, 4, 711.

10 Present, D. H., Rabinowitz, J. G., Banks, P. A., and Janowitz, H. D., New England Fournal of Medicine, 1969, $280,523$.

20 Perrett, A. D., Truelove, S. C., and Massarella, G. R., British Medical Fournal, 1968, 2, 466.

21 Morowitz, D. A., Block, G. E., and Kirsner, J. B., Gastroenterology, 1968, 55, 397

22 Hoffbrand, A. V., Stewart, J. S., Booth, C. C., and Mollin, D. L., British Medical fournal, 1968, 2, 71 .

23 McLeod, G. M., and Wiggins, H. S., Lancet, 1968, 1, 873.

2 Badley, B. W. D., Murphy, G. M., and Bouchier, I. A. D., Lancet, $1969,2,400$. without any increase in premature births, still births, abortions, or congenital abnormalities. Though one-quarter of the women felt better during the pregnancy, objective symptoms of Crohn's disease were unaltered. However, up to $40 \%$ were worse in the postpartum period. The probable explanation of this is the increase in steroid production that accompanies pregnancy and its decrease in the puerperium. There was no evidence that the pregnancy had an adverse effect on the overall course of the disease. Thus there is no medical necessity to advise termination of pregnancy simply because of Crohn's disease.

\section{Diets for Diabetics}

The diets used in the treatment of diabetes mellitus have evolved from the varieties of starvation of the pre-insulin era. At least in Great Britain the teaching of R. D. Lawrence has been influential. His initial "red and black line" diet," in which carbohydrate and non-carbohydrate foods were categorized, simplified the teaching and understanding of diets that regulated the intake of protein and fat as well as carbohydrate. The matter was further simplified by disregarding protein and fat foods in the diet of the average diabetic and regulating carbohydrate intake by the use of a 10-g. unit, or "portion," at present favoured by both the British Diabetic and Dietetic Associations. The main principle here is that the dietary treatment of diabetics should consist primarily in the regulation of carbohydrate intake. The amount allowed may vary from almost none in obese patients to a quantity matched in amount and distribution to the type of insulin or hypoglycaemic drug in use. Only in special cases need account be taken of the protein and fat content of the diet.

The Committee on Food and Nutrition of the American Diabetes Association ${ }^{2}$ has affirmed that the nutritional requirements of diabetics are in general the same as those for nondiabetics, but goes on to consider possible special needs. Among these the amount and type of fat in the diet is the most controversial. Since diabetes confers an increased risk of atherosclerotic vascular disease, a case can be made for advising diets rich in polyunsaturated fats. On this question the American committee gave no explicit guidance and left the decision to the individual physician. Such diets have already been prescribed for diabetic children, though not yet for long enough to judge whether atherosclerosis or other complications may be prevented or delayed. However, G. W. Chance and colleagues ${ }^{3}$ expressed disappointment at the degree to which the children kept to the recommended diet. While the nature of the diet and the fact that the patients were children or adolescents may have contributed to the high failure rate, the intimate nature of the trial is likely to have encouraged more patients to stick to the diet. than would patients less carefully scrutinized. Even with the much simpler

1 Lawrence, R. D., The Diabetic $A B C$, London, H. K. Lewis, 1929. 2 Committee on Food and Nutrition, Special Report, Diabetes, 1967, 16, 738. 3 Chance, G. W., Albutt, E. C., and Edkins, S. M., British Medical fournal, $1969,3,616$.

4 Bloom, A., Proceedings of the Royal Society of Medicine, 1967, 60, 149

Bloom, A., Proceedings of the Royal Society of Medicine, 1967, 60,
Jacobi, H. G., American fournal of Clinical Nutrition, 1954, 2, 343.

- Keen, H., Jarrett, R. J., Chlouverakis, C., and Boyns, D. R., Postgraduate Medical fournal, 1968, 44, 960.

7 Levy, R. I., and Glueck, C. J., Archives of Internal Medicine, 1969, 123, 220.

8 American Heart Association Monograph, No. 28, Report of the Diet-Heart Review Panel of the National Heart Institute. New York, 1969. 
carbohydrate-regulated diet too few patients keep to the instructions, as the paper by Sir Ronald Tunbridge and Dr. J. H. Wetherill at page 78 of the B.M. F. this week shows. Similarly disappointing results have been previously reported. ${ }^{46}$

Two questions arise from these observations. Firstly, why do diabetic patients not adhere to their recommended diets? And, secondly, does it matter if they do not? Unfortunately a clear answer can be given to neither. Perhaps inadequate advice by the doctor, poor motivation in the patient, and in some cases cost may explain why patients lapse from their diet, but evidence for the relative contribution of any of these is lacking. Tunbridge and Wetherill point out that the diabetic diet is more expensive than one giving free choice, but their data do not suggest how much of a deterrent this is. Nor do we know whether poor adherence to diet always matters. Some benefits from the diet are obvious, such as the improvement in glucose tolerance often observed äfter loss of weight, and balancing the carbohydrate against the insulin should prevent wild swings of blood sugar. In general, though, it may be argued that achieving and maintaining ideal weight is more important than the actual number of calories consumed. Moreover in some cases failure to keep to a prescribed diet may simply indicate the irrelevance of that diet to the patient's health. If true, this may also partly explain the lack of relationship between dietary intake and diabetic control found by both Tunbridge and Wetherill and by A. Bloom. ${ }^{4}$

The main problem in the treatment of diabetes, whether by diet or drugs, is that it is judged on blood-sugar control, and usually only in the short term. But the principal ill effects of diabetes are in the long term. If these, or some of them, are related to the levels of circulating lipids, then monitoring the lipids, with dietary changes to correct abnormalities in their levels, ${ }^{7}$ may come to be a usual procedure along with the conventional measurements of blood sugar. It would certainly make management more difficult, but perhaps more rational. Attempts to prevent atherosclerotic disease in non-diabetic persons by means of diet have given encouraging, if not entirely convincing, results. ${ }^{8}$ Similar trials with diabetic patients are required before embarking on the considerable task of recommending more complex regimens for the many who might need them. And these trials must evaluate the acceptability of a diet as well as its effectiveness.

\section{First Few Minutes of Spaceflight}

This weekend, all being well, the launch of another space capsule into the earth's orbit will start man's fifth journey toward the moon. Complex physiological adjustments are expected of astronauts during the first minutes of spaceflight. And it is the adaptation of their cardiovascular and respiratory systems to the environment of the capsule and to the acceleration during their launching into space on which the success of an interplanetary mission depends.

For three hours before the launch astronauts breathe $100 \%$ oxygen. This is the essential process of removing nitrogen from the body tissues to reduce the possibility of decompression sickness during the initial and rapid fall of cabin pressure. In the event of an immediate failure of the system which controls the initial fall in cabin pressurization to 6 pounds per square inch $(0.4 \mathrm{~kg}$. per sq. $\mathrm{cm}$.) the astronauts would be protected by their spacesuits. The suit is pressurized normally to 3.5 p.s.i. $(0.24 \mathrm{~kg}$. per sq. cm.), and under these circumstances the symptoms of decompression sickness may appear. Such an emergency might persuade the Mission Control to end the flight, but the immediate response would be to increase the suit pressure to above its usual working level. This would be in the region of 5 p.s.i. $(0.35 \mathrm{~kg}$. per sq. $\mathrm{cm}$.) and is likely to provide relief from mild symptoms of decompression in many cases. If the spaceflight was to continue restoration of cabin pressure would be essential, but the protection afforded by the suit would provide an effective environment while awaiting re-entry during the first orbit of the earth.

During the launch of an Apollo spacecraft the astronauts experience accelerations near to $4 \mathrm{~g}$. The increased gravitational stress passes across the chest and does not therefore have any serious effect on the circulation to the brain. But many studies have shown that such forces interfere with the ventilation and perfusion of the lungs, and it has been observed that during accelerations around $4 \mathrm{~g}$ the oxygen saturation of the blood falls by nearly $20 \%$. In effect a mild form of pulmonary atelectasis develops in astronauts breathing $100 \%$ oxygen during the launch which can usually be cleared by forced ventilation.

Having adapted to these changes in his environment the final adjustment required of the astronaut is to weightlessness. Injection into the earth's orbit occurs about 11 or 12 minutes after blast-off, and the changes in the cardiovascular system at this time are complex and not completely understood. An important change is the reduction in blood volume (up to $15 \%$ in some astronauts), which is presumably initiated by distension of the central vasculature as blood pools from the legs into the thorax. It is the reduction of blood volume and perhaps other changes, such as reduced venomstor tone following prolonged weightlessness, which leads to orthostatic hypotension on return to the earth.

\section{Teething Troubles}

In a review of problems of teething, R. S. Illingworth ${ }^{1}$ stated there is no evidence that teething causes convulsions, fever, bronchitis, or diarrhoea. He noted that disastrous mis takes are still made by ascribing such symptoms to teething. The result may be, for instance, that a baby reaches hospital moribund from pyogenic meningitis and convulsions which had been put down to his "teeth." Arvi Tasanen, ${ }^{2}$ in Finland, has now proved conclusively that there is no connexion between teething and convulsions, fever, diarrhoea, or bronchitis. He even showed that teething did not cause sleep disturbance by night but that it did increase daytime restlessness, finger sucking, gum rubbing, and drooling, sometimes with a temporary loss of appetite. It is perhaps going a bit too far to say that "teething produces nothing but teeth." The eruption of a tooth through the gum does seem to

1 Illingworth, R. S., The Normal Child, 4th edn., London, Churchill. 1968.

2 Tasanen, A., Annales Paediatricae Fenniae, 1968, 14, Suppl. No. 29. 3 Guthrie, L., British Medical fournal, 1908, 2, 468.

- Rendle-Short, J., Proceedings of the Royal Society of Medicine, 1955,

5 Aegineta, Paulus, Works, c. 700, Translated Francis Adams, London, Sydenham Society, $1844,1,13$.

- Harris, $\mathbb{W}$., De Morbis Acutis Infantum, 1689. Translated John Martyn, London 1742, p. 91 .

7 Seward, M. H., British Dental fournal, 1969, $127,457$. 